\title{
A Case Study on Developmental Changes of Eleventh Graders' Scientific Inquiry Competences
}

\author{
Yu-Liang (Aldy) Chang ${ }^{1}$, Su-Chiao (Angel) Wu ${ }^{2 \star}$ \\ ${ }^{1}$ Graduate Institute of Educational Administration and Policy Development, National Chiayi University, TAIWAN \\ ${ }^{2}$ Department of Early Childhood Education, National Chiayi University, TAIWAN
}

Received 28 June 2017 • Revised 16 October 2017 - Accepted 27 October 2017

\begin{abstract}
The purpose of this study was to explore possible developmental changes of vocational high school students' scientific inquiry competence while they learned within the "Mechatronics" inquiry-based curriculum and instruction. A case study approach was employed in this study, while multiple resources of $7711^{\text {th }}$ graders' learning were collected and analyzed by using the editing analytic techniques. During the process of this two-year study, there were 11 changes of students' competence extracted from the data collected. These changes were inducted into 6 categories of scientific inquiry competences and then finally formed three themes, "basic competence, advanced competence, and critical competence". The result of this study was reported as a developmental triad of students' scientific inquiry competences. Based on discussions, as teachers, we have to actively implement the real-life problem-solving teaching practice to enhance students' scientific inquiry competences. The findings of this study also provided the insight that how teachers understood the scope and sequence in designing inquiry-based curricula. Finally, the dialogue between the findings and the literature reminded us that students' scientific inquiry competences could not be cultivated in a short time; instead, a long-term and context-driven curriculum design is the cornerstone to develop their competences for future learning and life.
\end{abstract}

Keywords: scientific competence, scientific inquiry competence, vocational high school, inquiry-based teaching and learning

\section{INTRODUCTION}

In this technology-rich society, technology products were closely bounded with people's life. Thus, cultivating scientific competence is so important for promoting one's capability of using technological knowledge in daily life situations. In fact, developing citizens' scientific competence has become a global trend of science education around the world (AAAS, 1993; Bybee, 1997; Cajas, 1999; Chin, 2007; Cross, 1999; Cross \& Price, 1999; Ministry of Education, Taiwan, 2007; National Research Council [NRC], 1996). It is also an indicator of national competitiveness since it is beneficial for national economy and social welfare, as well as being advantageous for the decision-making of all public policies. Based on this developing trend, various educational policies and projects both in the United State and Taiwan (Lederman, Lederman \& Antink, 2013; Rithchie \& Rigano, 1996; Roth, 1995; Yen \& Huang, 1999) were implemented in which students were equipped with scientific knowledge and capability through the teaching and learning process of scientific inquiry; for instance, Project 2016 (by American Association for Advancement of Science [AAAS], 1989), National Science Education Standards [NSES] by NRC (1996), Next Generation Science Standards [NGSS] by NGSS Lead States (2013), and both Grade 1-9 Curriculum and 12-year Basic Education Guidelines in Taiwan by Ministry of Education, Taiwan $(2000,2014)$. Besides, in the "Science Education Whitepaper", announced by Ministry of Education, Taiwan (2007), it indicated that the significance of cultivating students' scientific competence in science education. Through the learning process of scientific inquiry in every classroom, students will not only acquire adequate scientific knowledge and skills and form a habit of scientific thinking but also apply what they learn in solving problems faced in the real world, which may also lead to a comprehensive understanding of the nature of science. Actually, what students need in confronting possible 


\section{Contribution of this paper to the literature}

- Three themes (named as basic competence, advanced competence, and critical competence), six categories, and eleven developmental changes of the targeted students' scientific inquiry competence were generated for further improvements and future studies.

- These findings also provide insights for teachers who want to observe students' inquiry-based learning process, as well as furnishing teachers with better ideas about the scope and sequence of designing inquirybased curriculum and instruction.

- The targeted vocational high-school students achieved the designated goals that would disenthrall themselves from the limitation of the traditional learning context and, in turn, allow them to pursue better learning experiences and life expectations in the future.

challenges in the future are the capability of asking appropriate questions and solving problems through scientific inquiry processes, which is the origin of creativity and innovation, instead of just memorizing irrelevant scientific knowledge for examinations (Hsiao, 2010). For teachers, they have to teach in an inquiry approach and encourage their students to actively engage in scientific inquiry in the whole learning process and propose diverse thoughts in promoting more advanced discussions and interactions for future improvements (Bybee \& DeBoer, 1994; Lubben \& Miller, 1996).

In regard to the evaluation of scientific competence, most of studies and international comparative assessment studies (e.g. "Trends in Mathematics and Science Study [TIMSS]" and "The Programe for International Student Assessment [PISA]) were conducted quantitatively, where the developmental process of students' scientific competence and its contextual interactions with teaching and learning were not able to be evaluated and exhibited qualitatively. Besides, studies of scientific competence domestically and internationally focused more on the three aspects separately: scientific attitude (e.g. Moore \& Sutman, 1970), scientific skills (e.g. Brown, 1977), and scientific knowledge (e.g. Lin, 1995; Ann \& Marcy, 2010). Also, fewer studies were conducted to discuss the connection between scientific competence and scientific inquiry (Chang, 2008). However, scientific inquiry competence is considered as the core nature of science education because this nature is able to inspire students to utilize what they learn in promoting their own understandings of the real world (Hazen, 2002). Therefore, how to develop our students' scientific inquiry competence for creating their own future stands at the center of the current education movement (Chang, 2015; Espinosa-Bueno et al., 2011). Based on these arguments, the main purpose of this study was to explore the developmental changes of the targeted vocational high school students' scientific inquiry competence while learning through an interdisciplinary and technology-infused curriculum with the inquiry-based instruction.

\section{THEORETICAL FRAMEWORK}

\section{Scientific Competence}

Kulgemeyer \& Schecker (2014) mentioned that the concept of competence in science education was defined as "a disposition that enables a person to perform successfully in content-related, complex and demanding problem situations" (p. 258). Shavelson (2010) also indicated that competence is "a physical or intellectual ability", "a performance capacity", or even "an underlying complex ability" (p. 44). Science is knowledge or a system of knowledge covering general truths or the operation of general laws especially as obtained and tested through scientific method (e.g. observation, experimentation, control, measurement, and analysis), which concerned with the physical world and its phenomena. Based on these viewpoints, scientific competence could be recognized as one's potential characteristics to successfully accomplish the designated scientific tasks, such as designing and executing a scientific experiment that is relevant to the real world situations (Kulgemeyer \& Schecker, 2014). Scientific competence is composed of three aspects, i.e. knowledge, capability, and attitude (Chin, 2007). That is to say, possessing scientific competence means one can find potential problems, form new ideas, and explain existed phenomena with scientific knowledge when they faced with science-related issues, personal decision, citizen participation, cultural affairs and economic development; then, conclusions can be drawn from scientific evidences (Organization for Economic Co-operation and Development [OECD], 2007; National Center for Education Statistics [NCES], 2012).

Before 1980's, nature of science, science and society, and science and humanity were viewed as core concepts of scientific competence because of its interrelation between science and society (Pella, 1967; Showalter, 1974; Shen, 1975). However, this perspective neglected the aim of scientific education, which emphasized that scientific education should provide knowledge and skill for students to deal with their personal or public issues with intelligent attitude and, in turn, to find their own value (DeBore, 1991; Keeves \& Aikenhead, 1995). After 1980's, it 
turned to focus more on gradations of the content of scientific competence, which emphasized concept and knowledge of science and formed the value system. Further, the process of solving problems, the capacity of decision-making, and the interaction with society were gradually considered as important parts of one's scientific competence (AAAS, 1989; Bybee, 1997; Chin, 2007; Durant, 1993; NRC, 1996; Shamos, 1995). Nowadays, science affects everyone's daily life; therefore, the more people support it, the more development it can reach (Barbro \& Johan, 2013; Durant, Evans, \& Thomas, 1989; Lee \& Chang, 2005). In this democratic era, all citizens have the right to participate in discussions of the formulation of public policies. In order to maximize the benefits of public policies, government officials, law makers, and the people all need to possess desirable scientific competence, in which all public issues are discussed based on various perspectives and examined through scientific approaches. In this way, the better public decisions will be made while the negative effects of scientific development will be minimized (Hsu, 2006). Apparently, enhancing all citizens' scientific competence is at the core of all current educational movements.

Besides, scientific competence "needs to be observed in real-life situations" (Shavelson, 2010, p. 44). Lin (1999) also indicated that dimensions and its developmental gradations of scientific competence should be properly adjusted based on various learning environments. Instead of expecting immediate changes, educators must understand that the development of scientific competence is a dynamic process. During the inquiry learning process, students can learn how to solve problems faced in real-world situations, where teachers are able to both diagnose their students' learning performance and, accordingly, try to adjust the teaching for further cultivating students' scientific competence.

\section{Scientific Inquiry Competence}

As mentioned above, cultivating students' capability of conducting scientific inquiry stands at the center of current trends in science education. Applying inquiry-based teaching and learning in all classrooms becomes popular because students' scientific competence is enhanced within this enriched environment and during the entire process (Gejda \& LaRocco, 2006). As Bruner (1967) argued, instead of being passive receivers, students should be active explorers during the learning process. This thought was confirmed by the NSES (NRC, 1996, p. 23), scientific inquiry "refers to the activities of students in which they develop knowledge and understanding of scientific ideas, as well as an understanding of how scientists study the natural world". In fact, science is not only a process but a body of knowledge (NRC, 1996). Chang and Wu (2015) also concluded that, "scientific inquiry has been emphasized as a set of pedagogical methods that represents scientific practices and promotes students to acquire content knowledge through a problem solving process" (p. 38). Later on, Center for Science Mathematics and Engineering Education (CSMEE, 2000) proposed that inquiry is a multi-dimension activity, which involves in the following actions: making observations; posing questions; examining books and other sources of information to see what is already known; planning investigations; evaluating current conclusions based on experimental evidences; using tools to gather, analyze, and interpret data; proposing answers, explanations, predictions, and discussing possible consequences. Besides, it also requires identifying assumptions, conducting critical and logical thinking, and looking for alternative explanations.

Moreover, empirical evidences from previous studies (e.g. Barak \& Shakhman, 2008; Fishman et al., 2003; Luft, 2001; Marx, et al., 2004; Santos-Trigo, 2008) revealed that students' are able to make sense of what is taught, which lead to superior learning outcomes, in various disciplines as well as at different ages while teaching with an inquirybased approach. With regard to the science learning, inquiry-based teaching and learning is evidently beneficial to develop students' mindset of engaging, observation, reasoning, sharing, critical thinking, and problem solving (Chang and $\mathrm{Wu}, 2015$; Espinosa-Bueno et al., 2011). It is also effective for promoting their self-confidence and motivation in learning science since a fruitful and joyful learning setting is furnished and connected with their reallife experiences (Banerjee, 2010; Liu, et al., 2009), where they conduct scientific inquiries as scientists to "study the natural world and propose explanations based on the evidence derived from their work" (NRC, 1996, p. 23). Consequently, teaching students how to conduct scientific inquiry is an essential reform effort promoted in recent science education worldwide.

In this study, the 5E instructional Model was applied in designing the inquiry curriculum and instruction (Bybee, 1997; Bybee et al., 2006). There are five phases, i.e. engagement, exploration, explanation, elaboration, and evaluation, in this inquiry learning cycle (Bybee, et al., 2006). Students energetically engage in an inquiry environment, created by teachers, where they reveal real-life related questions or problems through observations, reach possible solutions grounded in various resources, conduct scientific experiments and explain corresponding findings in their own ways, exhibit what they learn from the processes for further clarifications and discussions (Atilhan, et al., 2014; Chang, 2015; Chang and Wu, 2015; Orgill \& Thomas, 2007). Grounded on this enriched learning experience, illustrated in NSES (NRC, 2000) and NGSS (NGSS Lead States, 2013), targeted scientific content knowledge, positive attitude, and essential capabilities are attained for future applications and improvements. By 


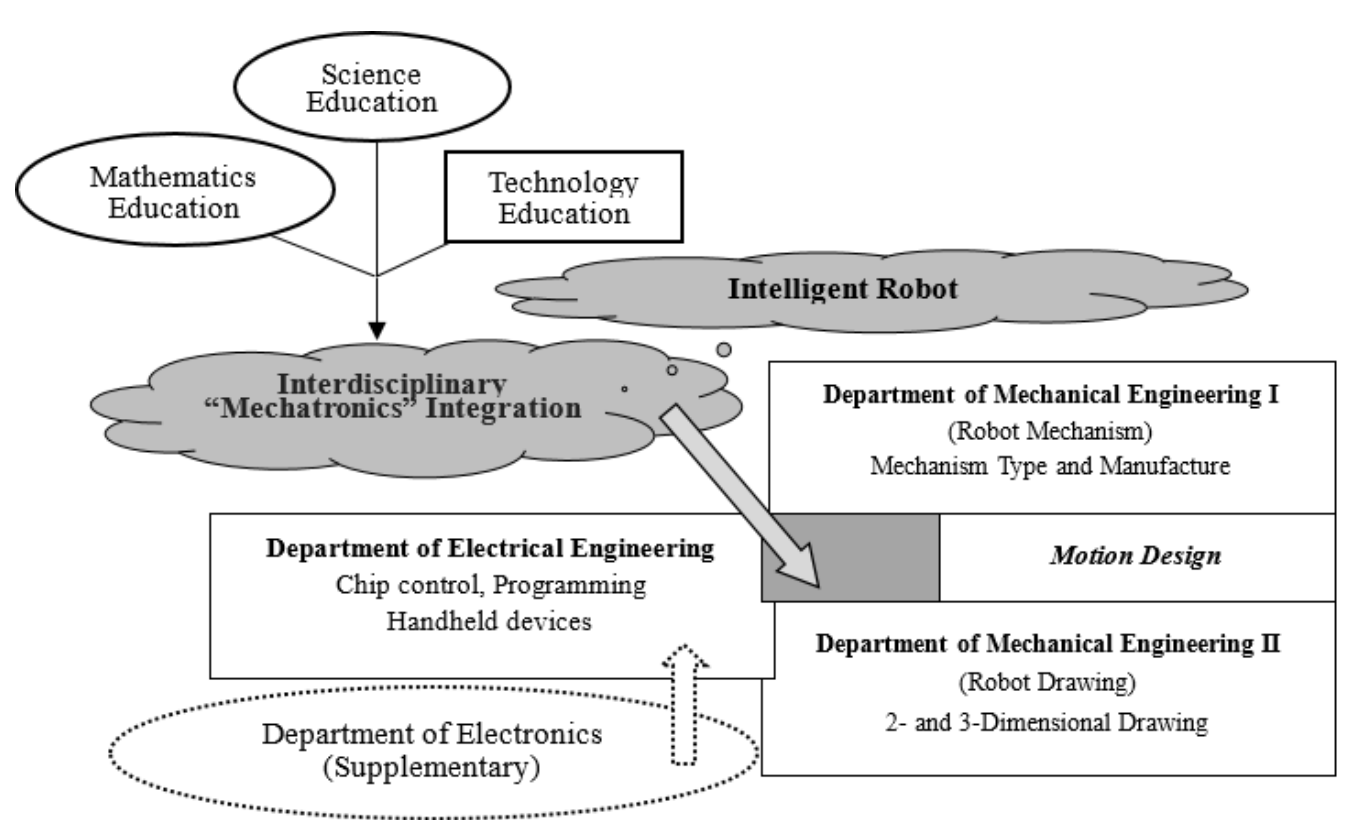

Figure 1. Integrated learning content (Chang, 2015, p. 42)

using this inquiry-based instructional model, an interdisciplinary and technology-infused curriculum was developed to reach the targeted objectives.

\section{RESEARCH DESIGN}

\section{Method and Participants}

This two-year study was one part of High Scope Project (phase II), which aimed to design an interdisciplinary and technology-infused curriculum with the inquiry-based instruction for advancing the quality of teaching and learning in the high school level (Chang, 2015). Another part of the project was to explore the targeted teachers' professional development in designing and implementing the designated inquiry-based curriculum and instruction ${ }^{1}$. In this study, a single-case design approach was employed to explore possible changes of the targeted students' scientific inquiry competence during and after the inquiry learning process (Yin, 2013). There were totally $7711^{\text {th }}$ graders from two departments (i.e. Department of Electrical Engineering [DEE] and Department of Mechanical Engineering [DME]) in a public vocational high school in southern Taiwan participating in this interdisciplinary project with the core content of "Mechatronics" intelligence robot. After receiving the inquirybased curriculum about the basic concepts of mechatronics in the $1^{\text {st }}$ year $\left(11^{\text {th }}\right.$ grade), these students then gathered together (i.e. in a group of 6 students from both departments) to take the research project course 2 hours a week in the $2^{\text {nd }}$ year (12 $12^{\text {th }}$ grade), as well as holding the group meeting periodically to discuss the project task and exchange thoughts and ideas with each other. There were 2 DEE teachers and 7 DME teachers who were responsible for collaboratively guiding them to learn in this inquiry-based learning process and accomplish their research projects. The designated inquiry-based curriculum was described in the previous publications (Chang, 2015); Figure 1 shows the integrated learning content.

\section{Data Collection and Analysis}

Data were mainly gathered from class observation [OB], interviews [IN], and various documents [DO] (e.g. working sheets, reflection notes, or related teaching and learning documents). Evidences gathered from both 9 teachers and 77 students were included in the whole data collection process (coding: 102912-S8/T1/R, 102912IN/OB/DO). Students' interviews included focus group interviews (4 times) and formal individual interviews (3 times or more for each participant); as well as lots of informal and follow-up interviews while needed. Classroom observations were executed during the whole learning process, including the regular courses, the project tasks and discussions, where all learning events were recorded and documents of all students' works were collected purposefully. For teachers, data were gathered from interviews, classroom observations, reflection notes, meeting records, and related teaching materials. Based on the theoretical framework of scientific inquiry competence, the original codes used were centered on three topics for data collection: thoughts and reflections about the inquirybased instruction, understandings towards inquiry-based learning (including the content), and the status that 
students applied what they learned to conduct the research project. As mentioned above, a single-case design was employed in this two-year study (Yin, 2013), where a longitudinal case was observed to reach how certain conditions changed (i.e. students' scientific inquiry competence) overtime. The targeted previously developed theory (e.g. inquiry-based approach) was used as a template with which to compare the empirical results of this case study. For example, if two or more students had similar behaviors within a specific context, this phenomenon would be marked for a follow-up exploration. Later on, if more than half of all students' performance in this phenomenon was aligned with the targeted theory, this literal replication would be claimed.

Data gathered were categorized and pre-analyzed by five steps (Thomas, 2000): preparation of raw data files, closed reading of text, creation of categories, overlapping coding and uncoded text, continuing revision and refinement of category system. Both editing and immersion analytic techniques were then employed for further analyses (Crabtree \& Miller, 1999). Through applying the organizing code topics mentioned above, the editing analytic system focused on students' scientific inquiry competence in the whole learning process. Because of the exploratory character of this study, the immersion analytic system was used to explore possible changes of targeted students' competence, where the cycle of immersion was repeated until the described interpretation was approached (Crabtree \& Miller, 1999).

\section{FINDINGS}

Based on the data analyses, eleven changes of the targeted students' scientific inquiry competence were extracted from the data collected in this 2-year inquiry-based learning process. These eleven changes were then classified into six categories of scientific inquiry competence. Further, these six categories of competence formed three themes named as "basic competence, advanced competence and critical competence" (See Figure 2). Corresponding to those changes, the process of these students' inquiry competence development was exhibited to be a consecutive and gradually developed manner in the two-year learning period. As mentioned above, a singlecase design approach was employed for data collection and analysis (Yin, 2003). The eleven changes of the targeted students' scientific inquiry competence in this longitudinal study were generalized from the data corpus, which was aligned with the targeted theory (e.g. inquiry-based approach). In Figure 3, the dotted line represents the potential competences which haven't been observed or confirmed; the solid line represents the changes on the designated competences which have been noticed or verified. Echoing to the implementation of the inquiry-based curriculum and instruction with the content of "Mechatronics intelligent robot", three developmental gradations on these students' scientific inquiry competence were portrayed: "germination of basic inquiry competence", "robustness of advanced inquiry competence", and "evolvement of critical inquiry competence". In fact, the developmental change was reported only if more than two-thirds of all 77 students exhibited the targeted behavior/performance. Therefore, the developmental gradations of scientific inquiry competence in Figure 3 did not necessarily applied to all students, which could be considered as a limitation of this finding. However, these developmental changes were still beneficial for future improvements in similar contexts. 


\begin{tabular}{c}
\hline $\begin{array}{c}\text { Developmental Changes } \\
{[\text { From ....to...] }}\end{array}$ \\
$\rightarrow \quad \begin{array}{c}\text { Category of } \\
\text { Competence }\end{array}$ \\
$\begin{array}{c}\text { Theme of } \\
\text { Competence }\end{array}$ \\
\hline
\end{tabular}

Gradation I

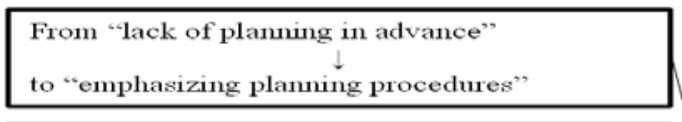

From "careless of what they learned"

to "taking notes actively while learning"

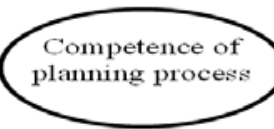

From "being afraid of failing"

to "being not easy to give up"

From "being less interested in anything in life"

to "being curious about everything in life"

Gradation II From "receiving knowledge passively"

From "receiving knowledge passively"
$\downarrow$
to "converting information actively"

From "relying on teacher's answer"

From "relying on teacher's answer"
$\downarrow$
to "solving problems themselves"

From "knowledge disconnected

with practical application'

to "hypothesizing with knowledge"

From "being afraid of hands-on activities"

to "learning by doing",

Competence of

positive attitude

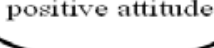

Germination of basic inquiry competence

Gradation III From "learning individually and silently"

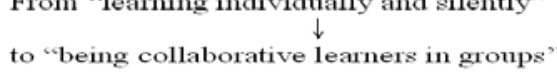

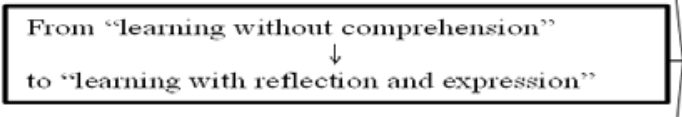

Competence of

problem-solving

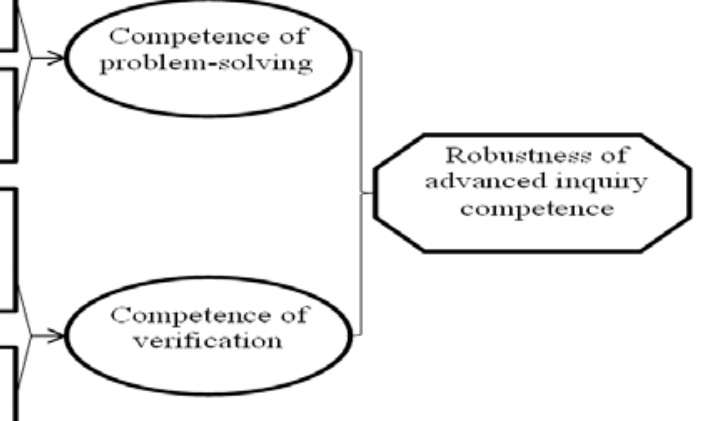

From "learning without logical thinking"

to "leaning with high-level cognitive thinking"

Figure 2. Analyses on developmental changes of students' scientific inquiry competence

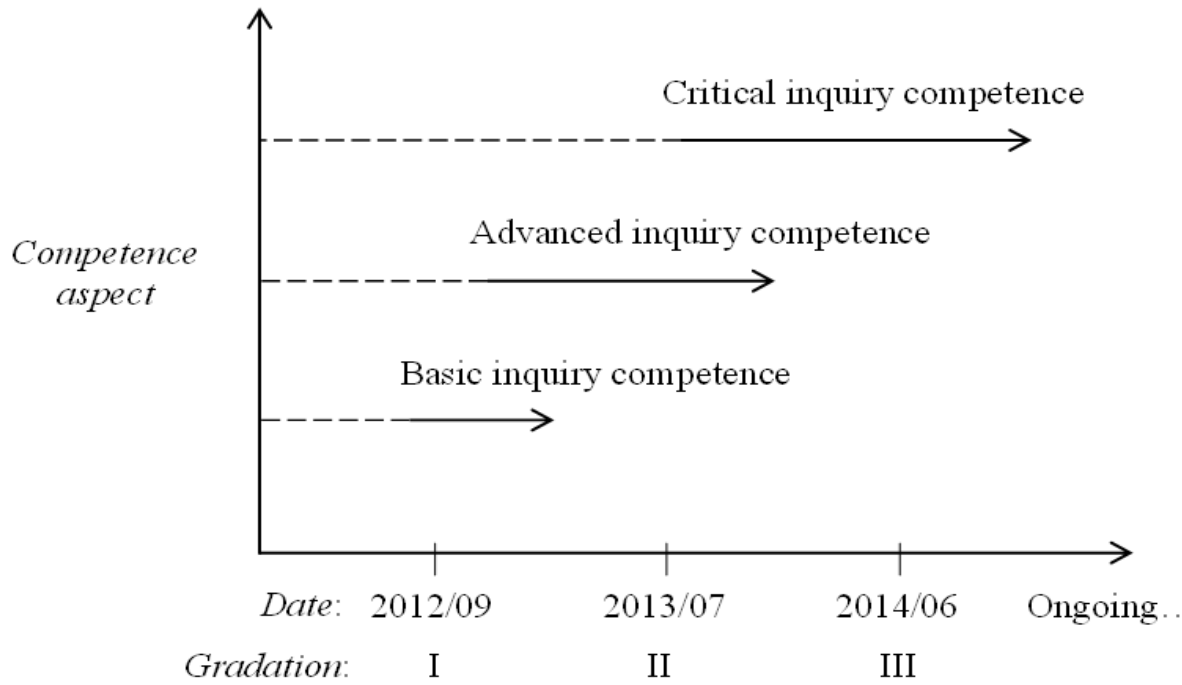

Figure 3. Developmental gradations of scientific inquiry competence 


\title{
Gradation I-Germination of Basic Inquiry Competence
}

\section{Competence of planning process}

\section{A. From "lack of planning in advance" to "emphasizing planning procedures"}

Similar to most vocational high schools, the targeted students were used to follow their teachers' commends instead of planning their own learning independently. One student said, "At beginning, we felt unfamiliar with lathe, benchwork, basic skills of milling machine; all we could do was just to follow our teacher's steps" (010713-S4). This phenomenon was confirmed in classroom observations, as recorded in one class activity: "When the teacher asked students to fill in the process plan of milling machine, most of students just sat there and waited for the teacher's commands" (010713-OB). In addition, it was found that students were not used to discuss and write down their plans before doing (e.g. assembling). When the teacher asked their students to try to design the assembling procedure and portray the action plan in advance, it's habitual that these students started to assemble the components without any discussion and plan. As S8 recalled, "Although we don't know what to do, we are used to dismantle or assemble the components when we saw them" (122012-S8). As a result, the targeted students were unfamiliar with "discussing, thinking, and planning before doing". However, this process is critical in the inquiry process, where students can recall their prior knowledge and skills and work cooperatively to think about "what's next" first. Therefore, before the targeted teachers joined this project, the teaching model was mainly to demonstrate how to do (e.g. dismantle or assemble) step by step so that students could be familiar with every basic assembling skill in a short time. After the inquiry teaching strategy was employed, students were gradually familiar with the process of "discussing, thinking, and planning before doing". Within this process, individual student, students in small groups, or the whole class could make a definition of variable, design the practiced process, arrange the way of presenting data collected, and predict the possible result. Most students understood that planning in advance was beneficial for later practices, while teachers identified this advantage too.

"Usually it would lead to poor results if only doing without advanced planning." (122012-T2)

"It wasted a lot of time when we directly dismantled the curved slide mechanism without planning in advance. Usually we repeated the processes again and again. Now, after discussing and planning the dismantling processes first and predicting possible problems might appear, we became more careful about every step in the whole process. This systematic method was so helpful that the speed of dismantling was faster than before." (120712-S2)

\begin{abstract}
"Before conducting the process of measurement and sketch, the first thing was to write down the procedure; for example, confirming what should be dismantled, coding all components, measuring the size of all components, distributing everyone's task, and so on. Moreover, we even listed some possible problems we might encounter in the process. With this advanced plan, we truly understood what we were doing. Even though the final result was not perfect, we knew what should be carefully done next time." (010713-S10)
\end{abstract}

Grounded on systematic guides in the inquiry teaching process, students were able to plan independently or cooperatively before they conducted the dismantling or assembling tasks. In this advanced planning stage, students could also apply their prior knowledge and skills into all practical processes. This basic competence of planning process disenthralled their past habits in the traditional teaching approach and inspired them to be familiar with and fond of the inquiry teaching approach.

\section{B. From "careless of what they learned" to "taking notes actively while learning"}

Along with the inquiry-based learning activities, these students gradually became more familiar with the handson learning process in the classrooms. With progressively adequate basic knowledge of "mechatronics" learned in fundamental courses in the $11^{\text {th }}$ grade level, they were more confident of accomplishing the learning tasks assigned by teachers with necessary practical operations. In fact, they had no idea about why "recording (by writing or drawing) their operational procedures" was essential since they did not pay attentions to the lecturing content or fixed operational procedures in the traditional teaching and learning environment. Therefore, the demand of taking notes for them was fairly unnecessary and meaningless. As S1 said, "in fact, we often forget recording in the process" (121412-S1) and usually complained that "it's annoying that practicing (operating) and recording at the same time" (121412-S5). "We just needed to follow teacher's commands before..." (121512-S16), said S16. However, they gradually realized the importance of taking notes in the operational process because they found that these notes were truly helpful during the inquiry-based "learning by doing" process. 


\begin{abstract}
"The most impression thing was to blend a liquid formula for illumination. Because of being unable to determine the degree of illumination, we re-made it for many times. After adopting the way of taking pictures as records and simultaneously marking the ingredient we used, we found that it was faster and easier to obtain the right results." (073113-S22)

"One time, the teacher asked us to observe the ondometer and tried to write down the results with words and diagrams. Originally, we didn't know the purpose of using diagrams as records. But, we found that these notes and diagrams were so effective that we could compare the differences among them and reveal what we should do next. "(121412-S1)
\end{abstract}

Once these students felt the data or questions that they wrote down in the process was so handy and valuable in the learning process, they became to appreciate the use of taking notes since it could help them to both reduce the chance of making mistakes and find out possible solutions effectively. This strategy was also helpful for their learning in other courses. Besides, these notes were not only beneficial for students' learning but also valuable for teachers in recording students' learning profiles and assessing students' outcomes.

\title{
Competence of positive attitude
}

\section{A. From "being afraid of failing" to "being not easy to give up"}

At the beginning stage of this inquiry-based learning, students failed to freely apply what they learned before in this learning process because of fragment knowledge and less comprehension. This incomplete learning in the traditional classrooms led to an improper concept of "dichotomy" (i.e. only answering "yes/no" questions, or having right/wrong answers) and, in turn, caused that they were afraid of making mistakes and became meticulous in making any decision. As S10 recalled, "we kept checking text book and needed teacher's help at each step" (121412S10). Similarly, S2 expressed why they were so cautious in the learning process, "...because of being afraid of making mistakes; besides, we also wanted to know if our work was the same as other groups' works" (121412-S2). Therefore, students tried to frequently check to see whether their works were the same as stated in the text book or others. To avoid making mistakes, students usually compared their works with other groups or kept asking for the teacher's help. Sometime, they even stopped working and just awaited the teacher's answers while they faced difficulties or problems, which may derived from being dependent on their teacher's direct instruction (121812-R). In fact, in traditional classrooms, the main purpose of practicing (operating) was to only enhance students' proficiency of those operating skills by technically imitating the teacher's operations and then repeatedly using those skills to the level of mastery. However, in this way, students had no chances to attain true understandings of what they have learned or apply the learned knowledge into practice. As S23 said, "although we may learn the knowledge in the text book, we were still not sure that whether we could make it by ourselves or not" (121412-S10).

In order to change this teaching and learning style, teachers tried to employ a three-step procedure while teaching: First, students, as usual, were asked to practice one time according to the steps in the textbook, following with more independent practices on examples in the textbook. After certain amount of practices, the teacher asked students to critically think and discuss if there were different ways to accomplish those practicing examples in the textbook. Finally, the teacher proposed a theme (with various kinds of topics, but not limited in); students must work in small groups to plan and design their own projects and present their final products. In the last two steps, students were encouraged to propose any idea or attempt that might work for finish practices or projects. For example, one group of students talked about their ideas, "we tied to make a potting with automatic systems that could measure humidity and temperature and then watering automatically while needed" (042213-S2), said S2. They started to design this automatic potting with the hand drawing (i.e. a sketch) and finally accomplish this project with many experiments (i.e. actually planting to test the designed systems). Another group of students found that the professional high-price equipment or materials were not truly necessary for achieving the final goal in this project. "Originally, we wanted to make the lightening stairs with LED. But we found that aqueous solution maybe another choice and cheaper" (042413-S22). While students struggled with the high-price issue of LEDs, the teacher provided some indirect hints to allow them to search various types of lighting objects or strategies. Rather than giving up, this indirect instruction provided a good opportunity and encouragement for students to adjust their oriental thoughts from a serious of experiments and failures to eventually discover the final design of the lighting system. As S11 stated, "We did not want to give up! Even though we kept making mistakes, we all believed that what we needed to do was to find out what's wrong and kept re-designing the system...then, we would be successful eventually" (041813-S11). In this inquiry-based project, these students' mentality changed from a passive or undisciplined manner to an active and positive state. Teachers also understood that the prior knowledge and basic operational skills were essential to achieve the final project. However, if a teacher just asked students to do technical practices without the following inquiry-based project work, students may never attain meaningful understandings of what they learned nor being able to make realistic connections of theories (knowledge) and practices. Further, instead of just following teachers' instructions or direct orders, this three-step scaffolded teaching process not only furnished these students to be 
more confident and not afraid of making mistakes but also created a better learning environment where they could think critically and solve problems systematically. This dramatic attitude change, i.e. not easily giving up, authentically became a positive faith for these students while confronting difficulties or frustrations in the learning process.

\section{B. From "being less interested in anything in life" to "being curious about everything in life"}

At the beginning of study, T2 asked students in one class, "Anything you could think of that was the application of the concept of torque (or force) in your daily life?" (110612-OB). However, no one answered the question. It showed that their knowledge was unable to connect with the reality (i.e. life situations) because of the traditional instruction. This phenomenon reflected a fact that these students lacked the ability of observation and sensitivity, which was one of the fundamental abilities of scientific inquiry competence. In an after-class discussion, T3 mentioned that, "Most of students were none sense! They couldn't respond to my questions by using the knowledge they learned and making connections with their daily life. They lacked the ability of analogy" (112112-T3). In fact, students also thought that, starting from the elementary school level, the teaching content were not truly connected with their daily life. As S9 recalled, "We had the courses of observing plants in our elementary school; but, actually we just read from the text book without any observation. This was the way we learned science, form elementary to secondary levels" (112712-S9). Students lost their curiosity unconsciously since it was disenthralled by both the traditional instruction and the textbook. In the inquiry-based teaching process, the starting point of actual learning began with students' curiosity about reallife problems, which may lead to produce a series of actions in order to solve those problems. This process allowed students to arouse their resonance toward the question raised by the teacher in the class discussion activity. Once the teacher provided the opportunity for students to reflect the real-life situations to what have learned in the classroom, students would be reactively motivated to think about the possible connections and be interested in the learning content. S7's reflection just proved the abovementioned statement,

\footnotetext{
"We thought these technical terms were useless and hard to understand. However, after the teacher's brief introduction with actual examples from our daily life experience...such as the chair and pulleys, we surprisingly found that these products in our daily life were the application of 'torque'. It's truly fun." (112012-S7)
}

Another example was the teacher's introduction of the applications of the infrared module and buzzer. Students started to discuss enthusiastically about these applications. It clearly showed that their curiosity was gradually aroused.

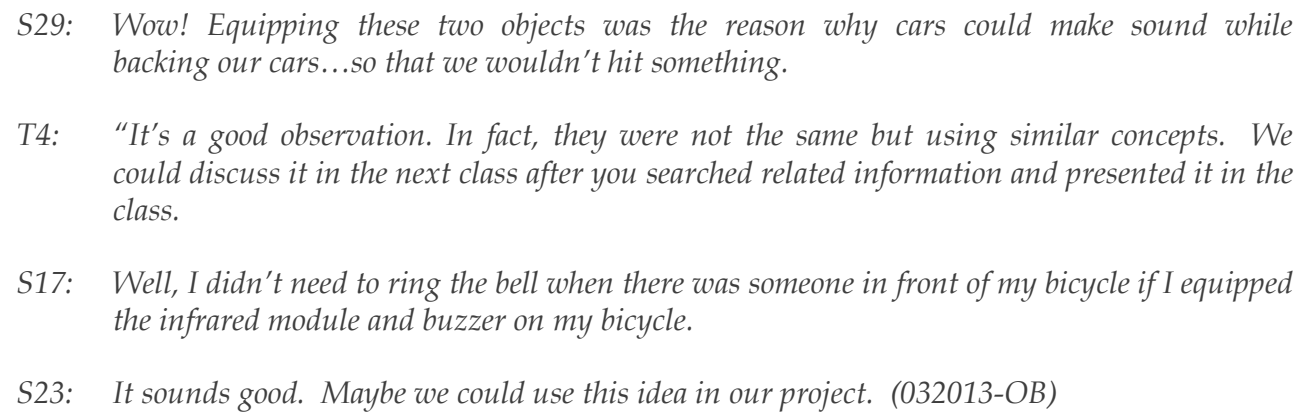

S23: It sounds good. Maybe we could use this idea in our project. (032013-OB)

In short, students would be more curious about things in their surroundings and raised relevant questions when they discover that what they learned could be meaningfully linked with their daily life. Instead of being not interested in learning, students would keep searching for better solutions and expect the moment happened while solving the problems.

\section{Gradation II - Robustness of Advanced Inquiry Competence}

\section{Competence of problem-solving}

\section{A. From "receiving knowledge passively" to "converting information actively"}

For a long time, the vocational education system emphasized technical trainings instead of the focus on theories and the cultivation of thinking. Traditionally, in order to reduce the knowledge gap between the middle school and the vocational high school in a short period of time, teachers found the traditional teaching method (e.g. direct teaching-lecturing) more effective. This phenomenon was clearly observed at the begging stage of this study. As S5 mentioned, "we didn't have chances to present or discuss in those 'theory' courses" (112712-S5). At the beginning stage, when teachers proposed a topic and asked students to search for further information, they were usually at a 
loss. They only searched information from certain website on the internet and had no idea how to use keywords or find specific websites; of course, they did not know how to compare or construct the information they found. "I searched the answer on 'Yahoo! Answers' and selected the one that looked like the answer" (122112-S13), said S13. However, this meaningless searching was replaced by an organized strategy after receiving teachers' guidance several months later. S6 talked about the process they prepared their presentation,

\begin{abstract}
"Teachers asked us to collect some special slides. We may choose the information randomly appeared on the internet before. But, after teachers told us that we must think about how to use the information we searched, we selected 2 slides which could be better used later after comparisons and discussions." (042213-S6)
\end{abstract}

At beginning, teachers provided students a reference list with books and periodicals for searching useful information. T4 said,

\begin{abstract}
"At beginning, students didn't have enough abilities to make judgments, for example, where to find the right information or how to decide which information was useful. So, I chose some information for them first; within this reference list, they could search more appropriate information for the assignment. After having certain experiences, they may know where and how to find proper information themselves. (052013-T4)
\end{abstract}

In this inquiry-based learning process, it was an important step that students could collect data from reliable sources and, in turn, transform the data gathered into useful formats to solve the designated problems. In this way, students in different groups could gradually take advantage of various methods to collect targeted information and learn from each other. They could also learn how to sift out those valuable information or knowledge, after discussions, based on the topic in this project work. S10 described what they did for information searching,

\begin{abstract}
"The topic we chose was to compare the differences between the stepper motor and the servo motor. We first searched the introduction online about the two motors and selected the content corresponding to the textbook. But, the information we found on the internet was not enough. Therefore, we decided to search further information from the library. Later on, we organized a lot of information about the two motors in several books and made a chart to compare the differences between the two." (052713-S10)
\end{abstract}

Through these data gathering processes (starting from the first year - the "basic concepts of mechatronics" courses in $11^{\text {th }}$ grade), students gradually became active learners in the classroom where they were in charge of their own learning instead of receiving information or knowledge form teachers passively. Even though they, as students of vocational high schools, were not good enough comparing to those who were high achievers in general high schools. They did learn basic skills of data collection or information searching and possess active attitude towards their learning. Besides, these students became more confident in dominating their own learning since their teachers provided relatively positive feedback through the performance assessment.

\title{
B. From "relying on teacher's answer" to "solving problems themselves"
}

In traditional classrooms, students were used to ask their teachers for help when they had questions, experienced difficulties, or faced problems. This phenomenon still existed in vocational high schools because of the test-oriented instruction; as known, entering universities were so easy in Taiwan for all high-school students. As S8 said, if we had questions, "teachers would tell us the answer directly if we asked them" (102912-S8). In fact, these were common questions you could hear in the classrooms: "Teacher! How to do it?"; or "Teacher! Why it didn't work?" (102912-O). It was an ordinary episode that students relied on their teachers' instruction (e.g. orders, or answers), which led to the opportunity they could solve problems themselves. Furthermore, there was no such a specific course or lessons that taught these students the designated problem-solving skills, or they were not given a chance to solve problems themselves. Thus, it was not surprising that they had no idea how to solve problems since they were not educated.

With those inquiry-based learning experiences, students were familiar that their teachers would not give them direct orders and answers as before. For the project courses in 12th grade (2nd year), they were also asked to observe, discuss, and discover what were the main problems and how to solve these problems while designing their own project products (e.g. robots). As S3 recalled, "We would seek for teachers' help when facing problems or just gave up. But now, teachers just gave us guidance or hints and had us solve the problems by ourselves" (053013-S3). Rather than awaiting for answers, S2 described what they did to find answers,

\footnotetext{
"In the past, we just listened to teachers' lecture and waited for answers if we had any problem. But now, we would search for the designated information by following teachers' hints. You know, although it cost more efforts and we needed to spend more extra time to finish it, we felt we were achieving something while ascertaining the answer." (061313-S2)
} 
As stated above, students had basic capability of searching or collecting useful information. However, they faced another challenge while actually conducting the research project (i.e. designing their own products in groups). "Sometimes we couldn't find the right information, especially for those problems occurred in the experiment/operative processes while designing our robots" (090913-S3). Teachers noticed these potential problems and employed the following strategies/steps to guide their students to solve problems: observe and record (phenomenon), discuss and define (problems), hypothesize (how to solve) and search (for possible answers), and make action plans and experiment (if failed, do the same process again) (041512-R). In this way, students were gradually used to apply these strategies/steps for their projects. S7 provided an example when they tried to assembling their own slide,

\begin{abstract}
"Last time, we finished assembling the slide and checked rotating speed of the motor; but, we found that the motor didn't work well. The Teacher let us figure out which part maybe wrong after observing another groups' successful works [note: The designs of the slides in different groups were different but having similar structures or components]. We assumed that the problem came from the wrong installation of some components; therefore, we checked our components again to make sure our assembling was right by comparing with other classmates' slides. Finally, we adjusted tightness of all components and it worked. Through these processes, we found that 'the screws were too tight' was the reason that the original assembling didn't work." (111913-S7)
\end{abstract}

In summary, once we give our students essential guidance and proper opportunities, they have the potential to accomplish all inquiry processes. In the abovementioned inquiry-based learning process, the targeted students worked collaboratively to solve the problems they faced. These successful experiences will become the foundation and the motivation for more future adventures.

\title{
Competence of verification
}

\section{A. From "knowledge disconnected with practical application" to "hypothesizing with knowledge"}

In recent years, credentialism has affected the teaching and learning orientation in vocational high schools in Taiwan. In vocational high schools, the main goal of this level's education was to cultivate professional or technical workers. After graduating from these schools, they will possess sufficient skills to find jobs. However, currently in vocational high schools, getting into a university for a bachelor degree becomes the first choice of most students (and/or parents). Thus, preparing for examinations are the main task of students in schools while teaching for tests are the core concern of teachers. This test-orientated instruction results in an odd phenomenon that these vocational high-school students may successfully memorize all the definitions and/or formulas and achieve high scores in the tests but fail to accomplish the operations or practices in the factory or lab (121212-R). In this study, the targeted teachers endeavored to change this meaningless teaching and learning by employing the inquiry-based instruction with more real life examples. These life-oriented learning activities provide more realistic experiences for these students to connect theories and practices in the classrooms, which also help them to re-ascertain their learning interests and clarify the authentic purposes of learning and life.

Once in a routine after-class meeting, teachers discussed their students' performance in the research project course and most of them praised students' works and efforts. They thought that students' learning attitude and ability in applying knowledge into practices did improve through those inquiry courses. Therefore, they discussed that maybe it was the time to raise the difficulty level of their assignments.

T1: I thought that they found out certain tips when I asked them to search some information and do the presentation, didn't you think so?

T3: Yes, I also found that they could catch the point more effectively in the operational process.

T7: Indeed, their plans or procures were probably not perfect, but at least they could finish the assignment themselves.

T4: The performances of some groups were good; maybe we should provide different or more difficult things for then to do.

T5: I I agreed! Perhaps we could let them try to examine the process reversely and find out what might be wrong or left behind in the whole process. (042413-DO)

Following this discussion, teachers gave the targeted students a new assignment recommended by $\mathrm{T} 5$ for further discussions. In this new assignment, students discovered there were still something missing; for instance: "We checked the curved slide again and wrote down the steps and components used" (051413-S8). "There were some 
components missing in our product" (051413-S13). "We missed some crucial steps and some of our assembling procedures were in a wrong order' (051413-S20). As these reflected their assembling processes, they could critically examine what had been done and detect possible problems themselves. Through these reflections, teachers could also perceive their students' improvement and achievement for the evaluation purpose. "We searched a lot of information about how to enhance the brightness. We assumed that adding more
light bulbs and using batteries with higher voltage would make our product brighter. After some
experiments, we found both two methods were effective but using high-voltage batteries was the better
choice." (072513-S12)

"We learned related theories in 11th grade; thus, we could predict the problems we might face in the process." (082113-S11)

Based on these students' actual performances in the process, their final products, and those reflections, the targeted teachers found that their students could apply their prior knowledge and practical experiences in their project tasks. Besides, the use of the performance assessment also allowed teachers to monitor their students' inquiry learning progress and actually perceived the adaptation and assimilation process of students' capabilities.

\section{B. From "being afraid of hands-on activities" to "learning by doing"}

As mentioned previously, students just memorized theories or formulas before they experienced this inquirybased learning process. Those practices they experienced were mostly followed their teachers' instruction with step by step imitations; actually, they didn't have chances to assemble any mechanism designed by themselves. Therefore, students usually felt bored about those technical operations or drills; for a long time, they were afraid of trying to operate or assemble mechanisms they were not familiar with. In the research project courses (2nd year, $12^{\text {th }}$ grade), students were to design a simple "joint mechanism" with the single axial structure. It was found that students were struggling how to do (design) it. As S18 said,

\footnotetext{
"We just looked at each other when we heard the teacher's instruction. Although we understood what he wanted us to do, we were still afraid of doing it and had no idea where to start; after all, we were never in touch with it." (043013-S18)
}

Indeed, every student (in groups) was at a loss as to what to do or was eager to call teachers for help (050713$\mathrm{OB})$. This phenomenon gradually changed after teachers attempted to provide guidance to every group and encourage them to try in the whole process. As observed, students progressively opened their minds to discuss in groups, observe other groups' works, and record all procedures in the design process. Even though some groups still failed to have a full design, they did experience how to design their own mechanisms and had practical opportunities to assemble it.

\footnotetext{
"We were afraid of making mistakes; but teachers always told us -it's ok to make mistakes. So, we gradually overcame the fear." (060513-S21)

"Teachers reminded us the available tools when we met problems. For example, the teacher wanted us to measure the voltage of analog tachometer. Some groups used oscilloscope, but we chose to use digital ammeter because it was convenient to read the data." (102313-S5)
}

Most students talked to us (teachers and researchers) about these hands-on experiences with more confidence than before (060513-R), which encouraged us to keep going this inquiry journey.

After accumulating a great deal of practical experiences, it was found that these students liked to engage in hands-on activities, as well as internalizing the inquiry knowledge and capability. As S16 said, "we can lower the mistakes if we outlined the procedure in our mind before operating" (111913-S16); he and most students understood that those note-talking and drawing tools were truly useful in this "learning by doing" process. Later on, it was also observed that students would look at their products and discuss with classmates if there were any more effective equipment or better resources (121713-OB). In fact, this comprehension did help them to become familiar with the authentic inquiry process and get used to apply it in their learning process. 


\title{
Gradation III - Evolvement of Critical Competence
}

\section{Competence of collaboration and thinking}

\section{A. From "learning individually and silently" to "being collaborative learners in groups"}

Limited by teachers' traditional instruction and tight class schedule, students of vocational high schools had less collaborative chance to discuss with classmates and present in the class; actually, this phenomenon might start from the middle school level. "Usually, we listen to teachers' lecture, less opportunity to work in groups for discussion or presentation" (100812-S5), said S5. Therefore, at the beginning stage of this study, it was found that the targeted 11th graders commonly lacked the capability of expression and communication because of receiving the traditional instruction for a long time. Since students were used to this "no-interaction" teaching model, it was clearly revealed that they felt confused about how to work collaboratively in groups (102912-OB). When they got stuck, the only thing they did was to ask their teachers for help: "How to discuss? What should I say while presenting?" (102912-OB). Another phenomenon was that only specific students were assigned to be the presenter(s) of their groups. It was heard that, "you (pointing to S5) were better than us....so you presented it" (112712-S4). Also, they didn't pay attention to other students' presentations since they failed to recognize that discussing with and listening to others was so important in the inquiry learning process. As mentioned, after receiving teachers' guidance on how to discuss and present, these students gradually found that this collaborative learning process was essential and beneficial. Therefore, they became to get used to work collaboratively in their own groups or even across groups. S10 said, "When we had problems, we would discuss first" (031213-S10). "It might not be the one in our group...We would discuss with classmates in other groups just for figuring out the answer" (042513-S2).

Progressively, some of groups could catch the key point when discussing and presenting, which reached teachers' expectation and attracting their classmates' eyes. They reflected that,

\begin{abstract}
"You know, what that group present always caught our attentions and made our eyes lighting up! You would wonder that why they had that kind of great ideas all the time...even though the discussion time was short." (051013-S9)

"I (we) liked to listen to the content of their presentations and tried to figure out why they could come up with those good ideas, plans, or products. So, if I had questions, I would just discuss with them." (101513-S2)
\end{abstract}

Furthermore, in addition to the group tasks, students could discuss in the whole-class learning process based on various results generated from all groups' presentations. Here was an example that one group's data on the rotational speed was different from others, which led to a discussion:

S36: I though the reason why they got an unusual data was that their mechanism was not well
assembled.

S29: Was it possible that they misread the data?

S18: I agreed with S36, it might be a wrong assembling.

S04: Yes, you might want to compare you mechanism with other groups to see if there were any difference.

S13: As I looked at their mechanism, I thought I found at least two differences.

S09: So, you guys could try to reassemble it and recheck the data, then we would know if the assembling was wrong or not. (123113-OB)

In this whole-class discussion, some students proposed their thoughts about the possibly wrong assembling, while one student (S13) did find out two assembling differences and another student (S09) made a suggestion. This conversation showed that this constructive communication positively stimulated the targeted students' learning. Actually, this kind of collaborative works occurred frequently in $12^{\text {th }}$ grade, which was full of brainstorming and scaffolding. In this way, students could learn from each other through discussing, listening, appreciating, and suggesting. They could also clarify something they didn't understand through this group or whole-class discussion process, where they expressed opinions, communicated with peers, and exchange and constructed ideas. As a result, they gradually became active and collaborative learners. 


\section{B. From "learning without comprehension" to "learning with reflection and expression"}

Before participating in this study, the targeted students just paid their attentions to memorize the content of textbooks without true understandings, which might originate from the test-oriented teaching in Taiwanese education system. Through intensive and technical drills, students were trained to fill in the paper-pencil examination (usually with multiple choice questions) and answer the questions in a speedy manner. At the beginning of this study, students were not used to the inquiry-based learning process, which they were asked to express their own thoughts through oral language or other representation tools (e.g. graph, table, etc.). In fact, they were afraid of making mistakes (i.e. saying something wrong). This fear may derive from past experiences in the traditional learning environment (i.e. both in elementary level and middle school level); actually less opportunity for discussions and presentations (especially in middle school level). Teachers perceived this potential problem; they expressed similar thoughts:

\section{T7: Usually, when we asked questions, no one would raise their hands or try to answer me. I thought they were afraid of saying something wrong. (112112-T7) \\ T1: For those who participated in the scientific exhibition and competition, they were comparatively better (in performance) than other students in the same class. However, they failed to say a word while practicing at school; in fact, every sentence was incomplete. (112812-T1)}

For most students, they had similar feeling about presenting, "you know, I was afraid of being ridiculed since I thought I was not good enough" (031913-S5). Therefore, teachers decided to give these students more opportunities to discuss with peers, propose questions, and present answers or idea. In this interactive process, students may obtain more chances to comprehend what they learn, ask what they doubt, and describe what they understand to others. Once they have these habits actively, their confidence would be promoted sequentially.

In the $2^{\text {nd }}$ year of this study (students became $12^{\text {th }}$ graders), the targeted students got used to discuss, question, and present in groups or the whole-class activities. It was found that students' presentations dramatically changed from "nothing to say" to "present in a well-organized manner and content" (123113-OB). Although a few students still needed to follow the PowerPoint or an original manuscript while presenting, most students could speak with fervor and assurance while discussing, questioning, and presenting. As S19 said, "I thought we all had impressive progress in the oral presentation. The most important thing was that we would review our presentations and discuss which part could be improved. This reflection did help us a lot for future improvement." (042513-S19). Through intensive observations, it was revealed that the accumulation of students' practical experiences on discussing, questioning, and presenting were beneficial for their development:
"They wrote reports after analyzing the data gathered in the operational processes. Then, they transformed these reports (with written words) into oral language and pictorial representations (e.g. graph, figure, and chart). Based on this transformation, they explained the findings with peers. Finally, they reviewed the whole process and reflected how to improve in the future." (051013-OB)

Grounded on this process, they gradually master main knacks and became more confident of their own presentations. In addition, it was ascertained that the targeted teachers gave more and more feedbacks to their students since these $12^{\text {th }}$ graders did have significant changes. As T1 mentioned, "Originally, there were only a few words or simple answers in their feedback and reflection sheets. However, at the end of the $2^{\text {nd }}$ year, they wrote a lot in these sheets; also, they gave higher scores on their own presentations." (051013-T1). In short, through positive communications and reflections in the inquiry process, students' learning enthusiasm was ignited and their learning motivation was promoted as well. This reflection and expression associated with the abovementioned collaborative peer learning did provide the necessary scaffolding for their current and future learning.

\section{From "learning without logical thinking" to "learning with high-level cognitive thinking"}

Traditionally, the single learning mode of "teacher lectures and students listen" was the main learning style in most classrooms, where the teacher serves as the origin of the knowledge. Limited by the time concern and the test-oriented practice, direct teaching is usually the only way of teaching, which memorization is more important than comprehension while preparing for examinations. Along with the implementation of this study, all teachers and their students devoted themselves to teaching and learning through the inquiry process, and continuously tried to reflect and disenthrall from the original constraint. Within the mechanics courses, it was supposed that students would just answer questions based on the content of textbooks while asking them how to measure torque. But surprisingly, students raised various kinds of ideas about formal or informal measuring tools (032813-OB). Later on, students could solve problems by connecting what they learned with their daily real-life experiences. This change showed that the level of students' learning (e.g. about the concept of torque) reached "comprehension or even application" instead of just memorization. At the end of the semester, the teacher asked students to measure and draw on the curved slide as the summative assessment of the course of computer assisted mechanical drawing. 
In this performance-based assessment, students needed to plan, disassemble, draw (sketch), measure, and collate, and finally draw the artwork. In this process, it was observed that students could authentically apply what they learned (e.g. theories and practices of analytic projection, scaling, dissembling) in finishing this assessment task. As S8 reflected, "I thought the learning process became joyful. What we learned before could be applied into this final assessment task. So, I realized that we learned so many things in this course." (052114-S8). Even though there were still some problems or mistakes occurred, students could eventually resolve them in groups and demonstrate their highlevel cognitive thinking in the whole process. Another remarkable outcome was one project product, named as "lighting up stairs", invented by a group of students in the whole-school project contest. Grounded on the topic of "home" and the concept of "mechatronics", students worked in groups to initiatively raise their proposals and create their products accordingly. This group of students tried to blend a liquid formula for illumination associated with the use of different lighting plates. In addition, by adding sensors on the handrail of the stairs, the lighting components could be automatically activated at night. In this design, this product could reach the purposes of energy saving, environmental protection, and safety and convenience. This creative innovation actually could serve an example of going beyond fixed textbooks or formal learning materials and moving into interdisciplinary leaning and problem-solving with real-life situations. In brief, these findings revealed that students became active learners in the classrooms and were responsible for their own learning. Their thinking was also promoted while participating in this inquiry learning process, where their creativity was inspired as well. In fact, this positive result did help for establish these students' scientific inquiry competence.

\section{CONCLUSIONS AND DISCUSSIONS}

\section{Cultivating Scientific Inquiry Competence for Actively Solving Daily-Life Problems}

Various developmental changes were evidently found on the aspects of students' scientific inquiry competence. In the mechanics courses, targeted students got rid of the traditional ways and learn how to apply the knowledge learned into practical process, which was well-arranged by their teachers with the designated inquiry-based approach (Chang \& Wu, 2015). In the whole process of solving problems, because of lacking of planning in advance, they became to realize the importance of actively taking notes and gradually had some reflections and conducted high-level cognitive thinking. Regarding the scientific attitude, students became active learners, who could transform the data collected to useful information, instead of just relying on teachers' orders. These findings just confirmed Bruner's (1967) argument, which students became active explorers during the learning process. About the social interaction, they could learn cooperatively with their classmates, as well as expressing ideas, explaining findings, presenting outcomes within small-group or the whole class activities. In addition, they learned how to respect others and reach a consensus, which were the best democratic lessons. They also acknowledged how to use technology to create a better life experience by finishing their project designs with the topic of "home". Most importantly, they obtained the abovementioned scientific inquiry competence within a joyful learning environment independently and/or collaboratively. Based on these findings, one can expect that the targeted students will become highly qualified citizens with desirable scientific competence. This achievement just parallels the argument of previous researchers (e.g. Barbro \& Johan, 2013; Durant, Evans, \& Thomas, 1989; Lee \& Chang, 2005) that all public issues are discussed according to various perspectives and examined through scientific approaches in this democratic era.

Further, reflecting on the new standards NGSS implemented in the United States (NGSS Lead States, 2013), it emphasizes the core spirit of interdisciplinary and the integration of science and technology, where students are able to raise a question, discover a life-related problem, and investigate, analyze, and propose possible answers. It also focuses more on a meaningful learning science where they can apply the knowledge base learned into practices with critical and creative thinking processes, in which context they become active learners (Bergmann \& Sams, 2012; Zappeet, al., 2009) and attain Dewey's philosophy of "learning by doing" in the whole learning process. As mentioned above, the targeted students' active learning attitude and behaviors also helped them, paralleling to the viewpoint of Kulgemeyer and Schecker (2014), to design and execute a scientific experiment that was relevant to the real world situations. Actually in this study, the targeted vocational high-school students achieved the abovementioned goals that would disenthrall themselves from the limitation of the traditional learning context and, in turn, allow them to pursue better learning experiences and life expectations in the future.

\section{Proposing Evidence-Driven Framework for Assessing Scientific Inquiry Competence}

As mentioned, most of studies and international comparative assessment studies (e.g. TIMSS, PISA) were conducted quantitatively, where the developmental process of students' scientific competence and its contextual interactions with teaching and learning were not able to be evaluated and exhibited qualitatively. Except using these paper-pencil tests, some scholars tried to use authentic assessment tools to assess students' scientific inquiry 
competence since "inquiry" is a multi-dimension activity (CSMEE, 2000). As Shavelson (2010) claimed, scientific competence "needs to be observed in real-life situations" (p. 44). For instant, Zachos et al. (2000) designed a series of structural tasks for investigating students' scientific inquiry capability, where their responses and reactions in the tasks were recorded for further analyses. Lunsford and Melear (2004) used students' learning portfolios, experimental records, and project products to assess the status and progress of their scientific inquiry competence as well as their learning outcomes. These authentic assessment tools were considered as better designs to gather processing information while teaching and learning, which conformed to ideas of NRC (1996), National Science Teacher Association [NSTA] (2004), and Ketelhut, Dede, and Clarke (2010). However, Zachos (2004) and JacobsSera, Hatfull, and Hanauer (2009) argued that it would be too difficult to observe students' scientific inquiry competence during the class by using authentic assessment tools because this evaluation might take a lot time to accomplish. Further, Wenning (2007) reflected that paper-pencil tests with multiple-choice questions could be only a reference or indicator of students' scientific inquiry competence but were not able to assess their high-level scientific inquiry competence (e.g. procedural knowledge, problem-solving ability, and ability of integration). Grounded on these debates, we applied a qualitative approach to collect and analyze multi-dimensional data of students' 2-year learning process, including records of their actual learning process, learning profiles (e.g. working sheets, reflections, notes), and learning outcomes (e.g. project products). Based on the findings and discussions, three themes (named as basic competence, advanced competence, and critical competence), six categories, and eleven changes of the targeted students' scientific inquiry competence were generated for further improvements and future studies (see Figure 2 for details). Because competence is "a physical or intellectual ability", "a performance capacity", or even "an underlying complex ability" (Shavelson, 2010, p. 44), these evidence-driven developmental changes and gradations of students' scientific inquiry competence can possibly serve as a balance of past quantitative (paper-pencil tests) and qualitative (authentic assessment tools) studies. These findings also provide insights for teachers who want to observe students' inquiry-based learning process, where students' mindset of engaging, observation, reasoning, sharing, critical thinking, and problem solving were able to be observed evidently and then developed correspondingly (Chang \& Wu, 2015; Espinosa-Bueno et al., 2011), as well as furnishing teachers with better ideas about the scope and sequence of designing inquiry-based curriculum and instruction. Similar to those empirical evidences from previous studies (e.g. Barak \& Shakhman, 2008; Fishman et al., 2003; Luft, 2001; Marx, et al., 2004; Santos-Trigo, 2008), by employing an inquiry-based approach while teaching and learning, students' can beneficially make sense of what is taught, which will also result in desirable learning outcomes in various disciplines and at different ages.

\section{Providing Enriched Inquiry-Based Teaching and Learning Environment for All People}

The use of inquiry-based teaching and learning gained acceptance more than a half of a century (Gallagher \& Harsch, 1997), which has been documented in various official and academic organizations (e.g. AAAS, 1989; CSMEE, 2000; Ministry of Education, Taiwan, 2000, 2014; NCES, 2012; NRC, 1996, 2000; NGSS Lead States, 2013). The cultivation of students' scientific competence is dynamic; one should never expect to see immediate changes in a short-term period (Holbrook \& Rannikmae, 2007; Lin, 1999; Rychen \& Salganik, 2003); instead, the development of students' high-level scientific inquiry competence needs to be considered as an accumulation of learning. Teachers in the classrooms must endeavor to provide differentiated learning opportunities to assist students' learning needs and diagnose students' development with multiple assessment tools (Chang \& Wu, 2015; Klein, 2006; Norris \& Phillips, 2003) in order to achieve the real goal of science education, which is to help them better understand the real world situations and solve life-related problems. In this study, we obtained paralleled findings about this long-tern developmental process, where students' scientific inquiry competence were gradually nurtured based on what specific conditions or difficulties they faced and how they figured the possible solutions out during the entire inquiry-based learning process. Paralleling to our previous findings (Chang \& Wu, 2015), this inquiry-based process was also beneficial for teachers' professional development, which could improve their teaching capability as well. This reminds us, as teacher educators, that we need to provide an enriched and joyful learning environment for training more qualified teachers to conduct inquiry-based teaching and learning in all practical settings. Moreover, inquiry-based teaching and learning are able to equip our students with essential scientific content knowledge and capabilities (e.g. experimenting, explaining, and presenting) (CSMEE, 2000; NRC, 2000; NGSS Lead States, 2013; Kulgemeyer \& Schecker, 2014) as well as positive and active learning attitude (Bybee, Powell \& Trowbridge, 2008; Bruner, 1967; Colburn \& Bianchini, 2000). In our study, it was found that students could think with diverse perspectives for solving the obstacles they confronted in the learning process, used their own words to present and defend their findings to peers, possessed positive and active attitude instead of giving up quickly, and collaborate with classmates through sharing and discussing ideas. For teachers, this result recommends that applying inquiry-based instruction is beneficial for advancing students' scientific inquiry competence. Especially in Taiwan, we are going to implement the new standards in 2019. Therefore, always thinking of how to design an inquiry-based curriculum and instruction deserves to be the core task of all teachers. 


\section{ENDNOTES}

An inquiry-based curriculum was cooperatively designed by a group of vocational high-school teachers and researchers/teacher educators under the "High Scope Project". The designated curriculum was implemented to enhance vocational high-school students' learning of advanced technology and their scientific inquiry competence. Because of the page limit, in this article, the targeted curriculum and instructional design is not described repeatedly, please refer to the previous article published in Eurasia journal (i.e. Chang \& Wu, 2015) for details, which includes a complete description of curriculum structure and content design.

\section{ACKNOWLEDGEMENTS}

This research was partially supported by MOST of Taiwan (NSC 101-2514-S-415-001; NSC 102-2514-S-415-001). The authors are grateful to the editor, reviewers, and participants.

\section{REFERENCES}

American Association for the Advancement of Science [AAAS] (1989). Science for all Americans: A Project 2061 report on literacy goals in science, mathematics and technology. Washington, DC: AAAS.

American Association for the Advancement of Science [AAAS] (1993). Benchmarks for science literacy: A Project 2061 report. New York: Oxford University Press.

Ann, C. H. K. \& Marcy, S-G. (2010). Inscriptional practices in undergraduate introductory science courses: A path toward improving prospective k-6 teachers understanding and teaching of science. Journal of the Scholarship of Teaching and Learning, 10(3), 58-88.

Atilhan, M., Eljack, F., Atilhan, H. M., Froyd, J. E., El-Halwagi, M., \& Mahalec, V. (2014). Inquiry guided learning in a chemical engineering core curriculum general instructional approach and specific application to the fluid mechanics case. International Journal of Engineering Education, 30(6), 1450-1460.

Barak, M. \& Shakhman, L. (2008). Reform-based science teaching: Teachers"e instructional practices and conceptions. Eurasia Journal of Mathematics, Science and Technology Education, 4(1), 11-20.

Barbro, G. \& Johan O. (2013). DEQUAL: A tool of investigating deliberative qualities in students' socio-scientific conversations. International Journal of Environment \& Science Education, 8(2), 319-338.

Bergmann, J., \& Sams, A. (2012). Flip your classroom: Reach every student in every class every day. Washington, DC: International Society for Technology in Education.

Brown, W. R. (1977). The effect of process-skill instruction on performance of preservice elementary teachers. Journal of Research Teaching, 14(1), 83-87.

Bruner, J. S. (1967). The Process of education. Cambridge, MA: Harvard University Press.

Bybee, R. W. (1997). Achieving scientific literacy: From purposes to practices. Portsmouth, NH: Heinemann.

Bybee, R. W., \& DeBoer, G. E. (1994). Research on goals for the science curriculum. In D. L. Gabel (ED.), Handbook of Research on science teaching and learning (pp. 357-388). New York: Macmillan Publishing Company.

Bybee, R. W., Taylor, J. A., Gardner, A., Van Scotter, P., Powell, J. C., Westbrook, A., \& Landes, N. (2006). The BSCS 5e instructional model: Origins and effectiveness, Colorado Springs, CO: A Report Prepared for the Office of Science Education, National Institutes of Health.

Bybee, R. W., Powell, J. C., and Trowbridge, L. W. (2008). Teaching secondary school science: Strategies for developing scientific literacy. Upper Saddle River, NJ: Pearson.

Cajas, F. (1999). Public understanding of science: Using technology to enhance school science in everyday life. International Journal of Science Education, 21(7), 765-773.

Chin, C. C. (2007). A reflection on the science education of Taiwan: The voice from the elites in Taiwan. Chinese Journal of Science Education, 15(6), 627-646.

Chang, L. Y. (2008). A study on science inquiry for gifted students. Bulletin of Special Education and Rehabilitation, 18, 51-71.

Chang, Y. L. (2015). Using mechatronics curriculum design in enhancing vocational high-school students' competence of scientific inquiry. International Journal of Engineering Education, 31(5), 1398-1409.

Chang, Y. L., \& Wu, H. H. (2015). A case study of increasing vocational high school teachers practices in designing interdisciplinary use of scientific inquiry in curriculum design. Eurasia Journal of Mathematics, Science, and Technology Education, 11(1), 37-51. 
Center for Science Mathematics and Engineering Education [CSMEE] (2000). Inquiry and the national science education standards: A guide for teaching and learning. Washington, DC: National Academy of Sciences.

Crabtree, B. F., \& Miller, W. L. (1999). Using codes and code manuals: A template organizing style of interpretation. In B. F. Crabtree \& W. L. Miller (Eds.), Doing qualitative research in primary care: Multiple strategies (2nd ed., pp. 163-177). Newbury Park, CA: Sage.

Cross, R. T. (1999). The public understanding of science: Implication for education. International Journal of Science Education, 21(7), 699-702.

Cross, R. T., \& Price, R. F. (1999). The responsibility of science and the public understanding of science. International Journal of Science Education, 21(7), 775-785.

Colburn, A., \& Bianchini, J. K. (2000). Teaching the nature of science through inquiry to prospective elementary teacher: A tale of researchers. Journal of Research in Science teaching, 37(2), 177-209.

DeBoer, G. E. (1991). A history of ideas in science education: Implications for practice. New York: Teachers College Press, Columbia University.

Durant, J. R. (1993). What is scientific literacy? In J. R. Durant, \& J. Gregory (Eds.), Science and culture in Europe (pp. 129-137). London: Science Museum.

Durant, J. R., Evans, G. A., \& Thomas, G. P. (1989). The public understanding of science, Nature, 340(6), 11-14.

Espinosa-Bueno, J. S., Labastida-Pina, D. V., Padilla-Martínez, K., \& Garritz A. (2011). Pedagogical content knowledge of inquiry: An instrument to assess it and its application to high school in-service science teachers. US-China Education Review, 8(5), 599-614.

Fishman, B. J., Marx, R. W., Best, S., \& Tal, T. R. (2003). Linking teacher and student learning to improve professional development in systemic reform. Teaching and Teacher Education, 19, 643-658.

Gallagher, J., \& Harsch, G. (1997). Scientific literacy: Science education and secondary school students. In W. Graeber \& C. Bolte. (Eds.). Scientific literacy: An international symposium (pp. 13-34). Kiel, Germany: Institut für die Pädagogik der Naturwissenschaften [IPN].

Gejda, L. M., \& LaRocco, D. J. (2006, October). Inquiry-based instruction in secondary science classrooms: A survey of teacher practice. Research paper presented at the 37th annual Northeast Educational Research Association Conference, Kerhonkson, NY.

Hazen, R. M. (2002). Why should you be scientifically literate? Retrieved on Oct. 15, 2012 from Action Bioscience website at http://www.actionbioscience.org/education/hazen.html

Holbrook, J., \& Rannikmae, M. (2007). The nature of science education for enhancing scientific literacy. International Journal of Science Education, 29(11), 1347-1362.

Hsu, Y. (2006). A survey of college students' scientific competence: An example of Kainan University. Journal of the Chinese for General Education, 9, 137-154.

Jacobs-Sera, D., Hatfull, G.F., and Hanauer, D.I. (2009). Assessing scientific inquiry. In Hanauer, I.D., Hatfull, G.F., \& Jacobs-Sera, D. (Eds.), Active assessment: Assessing scientific inquiry (pp. 31-43). New York: Springer.

Keeves, J., \& Aikenhead, G. (1995). Science curriculum in changing world. In B, J. Fraser \& H. J. Walberg (Eds.), Improving science education (pp. 13-45). Chicago, IL: The National Society for the Study of Education, University of Chicago Press.

Ketelhut, D.J., Dede, C., \& Clarke, J. (2010). A multi-user virtual environment for building higher order inquiry skills in science. British Journal of Educational Technology, 41(1), 56-68.

Klein, P. D. (2006). The challenges of science literacy: From the viewpoint of second-generation cognitive science. International Journal of Science Education, 28(2/3), 143-178.

Kulgemeyer, C., \& Schecker, H. (2014). Research on educational standards in German science education: Towards a model of student competences. Eurasia Journal of Mathematics, Science E Technology Education, 10(4), 257269.

Lederman, N. G., Lederman, J. S., \& Antink, A. (2013). Nature of science and scientific inquiry as contexts for the learning of science and achievement of scientific literacy. International Journal of Education in Mathematics, Science and Technology, 1(3), 138-147.

Lee, W.-C., \& Chang, C.-Y. (2005). Taiwan's secondary school teachers' expectations with regard to the earth science literacy of their students. Journal of Taiwan Normal University: Mathematics \& Science Education, 50(2), 1-27.

Lin, C. Y. (1995). The development and validation of the understanding of the nature of science scale. Science Education Monthly, 4(1), 1-58.

Lin, S. S. (1999). Reflection on scientific literacy. Science Education Monthly, 222, 16-25. 
Lubben, F., \& Millar, R. (1996). Children's ideas about the reliability of experimental data. International Journal of Science Education, 18(8), 955-968.

Lunsford, E., \& Melear, C.T. (2004). Using scoring rubrics to evaluate inquiry. Journal of College Science Teaching, 34(1), 34-38.

Marx, R. W., Blumenfeld, P. C., Krajcik, J. S., Fishman, B., Soloway, E., Geier. R., \& Tal, R. T. (2004). Inquiry-based science in the middle grades: Assessment of learning in urban systemic reform. Journal of Research in Science Teaching, 41(10), 1063-1080.

Ministry of Education, Taiwan (2000). Grade 1-9 Curriculum Guidelines. Taipei, Taiwan: Author.

Ministry of Education, Taiwan (2007). Science Education Whitepaper. Taipei, Taiwan: Author.

Ministry of Education, Taiwan (2014). 12-year Basic Education Curriculum Guidelines. Taipei, Taiwan: Author.

Moore, R. W., \& Sutman, F. X. (1970). The development, field test, and validation of an inventory of scientific attitudes. Journal of Research in Science Teaching, 7, 85-94.

National Center for Education Statistics [NCES] (2012). The condition of education 2012. Retrieved on Nov. 10, 2014 from http://nces.ed.gov/programs/coe

National Science Teacher Association [NSTA] (2004). Scientific inquiry. Retrieved on Oct. 20, 2014 from http://www.nsta.org/about/positions/inquiry.aspx

National Research Council [NRC] (1996). National Science Education Standards. Washington, DC: National Academy Press.

National Research Council [NRC] (2000). Inquiry and the national science education standards: A guide for teaching and learning. Washington, DC: National Academy Press.

NGSS Lead States (2013). Next generation science standards: For states, by states. Washington, DC: National Academies Press.

Norris, S. P., \& Phillips, L. M. (2003). How literacy in its fundamental sense is central to scientific literacy. Science Education, 87(2), 224-240.

Organization for Economic Co-operation and Development [OECD] (2007). Assessing scientific, and mathematical literacy. Paris: Author.

Orgill, M., \& Thomas, M. (2007). Analogies and the 5E model: Suggestions for using analogies in each phase of the 5E model. The science teacher, 74, 40-45.

Pella, M. O. (1967). Scientific Literacy and the High School Curriculum. School Science E Mathematics, 67, 346-356.

Rithchie, S. M., \& Rigano, D. L. (1996). Laboratory apprenticeship through a student research project. Journal of Research in Science Teaching, 33(7), 799-815.

Roth, W. M. (1995). Authentic school science: Knowing and learning in open-inquiry laboratories. Dordrecht: The Netherlands: Kluwen Academic Publishing.

Rychen, D. S., \& Salganik, L. H. (2003). A holistic model of competence. In D. S. Rychen and L. H. Salganik (Eds.), Key competencies for a successful life and a well-functioning society. (pp. 41-62). Cambridge, MA: Hogrefe \& Huber Publisher.

Santos-Trigo, M. (2008). An inquiry approach to construct instructional trajectories based on the use of digital technologies. Eurasia Journal of Mathematics, Science \& Technology Education, 4(4), 347-357.

Shavelson, R. (2010). On the measurement of competency. Empirical Research in Vocational Education and Training, 2, 43-65.

Shen, B. S. P. (1975). Science Literacy: The Public Need. The Sciences, 1, 27-29.

Showalter, V. (1974). What is unified science education? Program objectives and scientific literacy, 2, 1-6.

Shamos, M. H. (1995). The myth of scientific literacy. New Brunswick, NJ: Rutgers University

Thomas, J. W. (2000). A review of research on project-based learning. San Rafael, CA: Autodesk.

Wenning, C. (2007). Assessing inquiry skills as a component of scientific literacy. Journal of Physics Education Online, $4(2), 21-24$.

Yen, C. F., \& Huang, S. C. (1999). Student interactions in open-inquiry ecological research settings. Science Education Monthly, 11(2), 141-169.

Yin, R. K. (2013). Case study research: Design and methods (5th Ed.). Thousand Oaks, CA: Sage.

Zachos, P. (2004). Pendulum phenomena and the assessment of scientific inquiry capabilities. Science and Education, 13(7-8), 743-756. 
Zachos, P., Hick, T. L., Doanne, W. E., \& Sargent, C. (2000). Setting theoretical and empirical foundations for assessing scientific inquiry and discovery in educational programs. Journal of Research in Science Teaching, 37(9), 938-962.

Zappe, S., Leicht, R., Messner, J., Litzinger, T., \& Lee, H. W. (2009). Flipping the classroom to explore active learning in a large undergraduate course. In Proceedings of American Society for Engineering Education Annual Conference \& Exhibition. Retrieved on Nov. 15, 2014 from https://peer.asee.org/flipping-the-classroomto-explore-active-learning-in-a-large-undergraduate-course.pdf

\section{http://www.ejmste.com}

